\title{
Why, when, and how general practitioners restore endodontically treated teeth: a representative survey in Germany
}

\author{
Michael Naumann ${ }^{1,5}$ - Klaus W. Neuhaus ${ }^{2}$ - Manja Kölpin ${ }^{3}$ - Rainer Seemann ${ }^{2,4}$
}

Received: 10 March 2015 / Accepted: 4 June 2015 / Published online: 18 June 2015

(C) Springer-Verlag Berlin Heidelberg 2015

\begin{abstract}
Objective The purpose of this study was to assess current opinions, applied techniques, and materials for the restoration of endodontically treated teeth (ETT) in a nationwide survey in Germany.

Material and methods Completed questionnaires from 1,648 dentists were returned (response rate $63 \%$ ).

Results In general, posts were reported to be used more frequently $(51 \%)$ for indirect restorations than for direct restorations $(21 \%)$. Dentists restored anterior teeth $(65 \%)$ more frequently with direct restorations than posterior teeth (48\%). Compared to an earlier survey, fewer dentists stated that posttreatment stabilizes the remaining tooth structure. The ferrule effect as a key success factor was held by the vast majority of dentists ( $88 \%$ ). A trend towards adhesive techniques both for post placement and core build-up was observed. Composite resins $(49 \%)$ were reported to be used twice as much as zinc phosphate cement ( $24 \%$ ) for the luting of posts; composite resins were the core build-up material of choice $(75 \%)$. Amalgam was rarely used $(0.2 \%)$. Irrespective of the final
\end{abstract}

Michael Naumann

naumann@naumann-kiessling.de

1 Clinic for Prosthetic Dentistry, Department of Dentistry, University Clinic Ulm, Ulm, Germany

2 Department of Preventive, Restorative and Pediatric Dentistry, School of Dental Medicine, University of Bern, Bern, Switzerland

3 Department of Prosthetic Dentistry, Charité University Clinic CC03 Berlin, Berlin, Germany

4 DENTSPLY DeTrey, Konstanz, Germany

5 Department of Prosthetic Dentistry, Center of Dentistry, University of Ulm, Albert-Einstein-Allee 11, 89081 Ulm, Germany restoration, fiber posts were the most popular post material (46\% for telescopic crowns vs. $69 \%$ for single crowns). Conclusion Adhesive composite core build-ups with and without fiber posts were the predominant treatment approach to restore ETT in Germany. There was widespread agreement with the ferrule effect as a key restorative success factor for indirect restorations.

Clinical significance Today, it is general accepted that ferrule preparation is key. Glass-fiber posts appear to be most popular. Still different systems are used depending on type of final restoration, while the reasons to do so remain unclear.

Keywords Post-and-core technique $\cdot$ Dowel $\cdot$ Root . Root-treated teeth $\cdot$ Reconstruction

\section{Introduction}

Recently, a long-term randomized controlled study was published, documenting that post-endodontic restoration was clinically reliable, irrespective of the rigidity of the post-material used [1]. The relatively new types of so-called dentine-like glass-fiber posts do work when combined with composite resin core build-ups. The presence of a minimum of 1.5$2.0 \mathrm{~mm}$ wide ferrule preparation is the key success factor [2] as well as the amount of hard tissue loss [3-9]. Furthermore, the survival of endodontically treated teeth (ETT) is influenced by a variety of different parameters, which can only be partly controlled by the dentist, such as the number of adjacent teeth [10,11], occlusal contacts [12], position of the tooth in the dental arch [13, 14], apical status [15], collagen degradation [16], intermolecular cross-linking of the root dentine [17], remaining dentine wall thickness [14, 18-20], and type of final restoration $[9,11,13,21-23]$. 
It is generally accepted that the purpose of post placement is to retain a core foundation $[17,24]$ and not to reinforce an ETT [5, 25-27]. Despite their disadvantages concerning the integrity of the roots, screw-type posts were reported to be widely used [28-35]. Cast post-and-cores and prefabricated posts with composite resin foundations were found to result in comparable loads-to-fracture [36]. Dentists are confronted with a continuously growing number of different materials for post-endodontic restoration and with an increasing number of ETT needed to be restored [37]. However, the scientific literature provides numerous, mostly material-oriented, non-comparable, and thus eventually confusing in vitro studies [38]. Hence, it is not surprising that the manner in which postendodontic restorative care is performed does not always reflect the best available scientific evidence [39], but is rather influenced by geographic location, age, and speciality status [40]. Several surveys have been performed in various countries to elucidate which treatment concepts and materials for endodontic and post-endodontic restoration are favored by dental practitioners [32-35, 39-43]. The present survey was conducted to update a previously performed study [44] of similar content regarding current use of different post-andcore techniques to restore ETT by German dentists.

\section{Material and methods}

\section{Recruitment of the participants}

The survey was performed in the same manner as described for a previous nationwide survey organized by the authors [43]. The participating dental practitioners were selected randomly within five regions defined on the basis of postcode areas (two digits) in Germany. A commercially available database of German dental practitioners was used for the selection. Dental students exclusively hired and briefed to conduct this survey within a period of 4 months visited the selected dentists. After verbally explaining the objective of this survey, each participant received a questionnaire and a product sample of Smart Dentin Replacement (SDR, DENTSPLY DETREY, Konstanz, Germany) as incentive and in order to rate its suitability for directly restoring ETT. Besides this, the participants received no further compensation.

The participants were asked to return the questionnaire by fax. In total, 2,626 of the dentists initially agreed to participate. A total of 1,648 dentists returned the completed questionnaire, resulting in a response rate of $63 \%$. Non-responders were not reminded due to the anonymous character of this survey.

\section{Questionnaire}

A slightly modified, shortened version of the questionnaire previously used for a survey by the present research group in 2006 [44] was used. A cover letter stated the instructions, rationale, and purpose of this survey. The questionnaire contained 13 multiple-choice questions dealing in the first section with the treatment concept for ETT, and in the second section with questions related to materials and methods used for the treatment including questions regarding the specific use of flowable composites adopted from an earlier questionnaire [43]. Regarding the frequency of post placement, "seldom" was defined as an assumed need for post placement in up to $30 \%$ of ETT, "frequently" for between 30 to $70 \%$ of ETT, and "usually" for more than $70 \%$ of all ETT a cast restoration was planned for.

The following questions were posed (translation of the original German):

- "What percent of ETT do you insert a post for (A) direct restorations and (B) laboratory restorations?"

- "Are you of the opinion that a post does strengthen an ETT and reduces the probability of fracture?" Dentists could choose between "yes, in every case," "yes, but only when I cement the post adhesively," "yes, but only when I place the post conventionally," "no," or "other."

- "Are you of the opinion that envelopment of the ETT within sound dentine by a crown restoration (ferrule, ferrule effect) does increase the fracture resistance of ETT?" Dentists were able to choose between "yes," "no," or "don't know."

- "Which type of cement do you use most frequently for endodontic post cementation?" Dentists could choose between "zinc phosphate cement," "polycarboxylate cement," "glass ionomer cement," "composite resin cement," or "other."

- "How frequently do you observe failures in the treatment of ETT?" Dentists could give the frequency of failures in percent for "loss of post retention," "root fracture," "crown fracture," "endodontic problems," or "other."

- "Which type of post do you use most frequently for the build-up of ETT, when the following restorations are planned?" Dentists could choose between "glass-fiber posts," "metal posts (active as prefabricated posts)," "metal posts (passive as screws)," "cast post-and-cores," and "other" depending on the type of reconstruction planned such as "direct restorations," "single crowns," "fixed partial dentures," and "telescopic crown restorations as part of combined fixed-removable partial denture."

- "Which core build-up material do you use most frequently when a laboratory restoration is planned?" Dentists could choose between "amalgam," "composite resin," "glassionomer," or "composite-modified resins (compomers)."

- "Do you restore ETT with direct composite resin restoration?" Dentists could choose between "yes" and a number in percent for anterior and posterior teeth, respectively, or "no" or "only in very few cases." 
- "Which kind of adhesive do you use when restoring ETT with direct composite restorations?" Dentists could choose between "etch/rinse" and "self-etch."

- "Do you preferably use a flowable composite when restoring ETT with direct composite restorations?" The participants could choose between "yes" or "no."

- "Why do you use a flowable composite when restoring ETT with direct composite restorations?" This question was only asked those participants that stated they used flowables. They could choose from the following answers, and multiple answers were possible: "to avoid voids," "for better adaptation to the cavity wall," "as stress breaker," "to save time," "for a bacteria-tight seal," and "other reasons," which had to be named.

- "Why do you not use a flowable composite when restoring ETT with direct composite restorations?" This question was only asked to those participants that stated they did not use flowables. They could choose from the following answers, and multiple answers were possible: "because flowables show a higher shrinkage stress leading to leakage," "because of their lower mechanical strength," "because they cannot be sculpted," "because it doesn't give me a clinical advantage," and "other reasons," which had to be named.

- "Please rate the test material in comparison with your current filling material for restoring ETT with direct composite restorations in terms of time saving, simplicity of procedure, overall handling, creation of good proximal contacts, and internal adaptation." Each aspect had to be rated in comparison to the technique currently used by the dentist. The participant could choose between "better," "slightly better," "slightly worse," or "worse."

\section{Statistics}

The returned questionnaires were anonymized, and the data was analyzed using descriptive statistics (software package SPSS 19.0, SPSS Inc. Chicago, ILL, USA). Frequency distributions (for treatment philosophy including standard deviation) were used for descriptive statistical representation of the results.

\section{Results}

A total of 1,648 questionnaires were completed. The data focusing on the treatment concept is presented in Table 1 . According to this data, $51 \%$ of all dentists stated that they place a post frequently or always when an indirect restoration is planned, while $39 \%$ stated to do this seldom (Table 1). In the case of a direct restoration being used as a permanent
Table 1 Data focusing on treatment concept

\begin{tabular}{lc} 
How often do you place a post in directly restored ETT? \\
Seldom & $79 \%$ \\
Frequently & $11 \%$ \\
Always & $10 \%$ \\
How often do you place a post in laboratory restored ETT? \\
Seldom & $39 \%$ \\
Frequently & $28 \%$ \\
Always & $33 \%$ \\
Do you believe that a post reinforces an ETT and reduces the fracture \\
probability? \\
Yes, definitely \\
Yes, if adhesively luted \\
Yes, if conventionally luted \\
No & $30 \%$ \\
Other & $1 \%$ \\
\hline
\end{tabular}

Do you believe that reducing the level of the finishing line below the core foundation following post cementation increases the fracture resistance?

\begin{tabular}{ll} 
Yes & $88 \%$ \\
No & $7 \%$ \\
Not specified & $5 \%$ \\
\hline
\end{tabular}

ETT endodontically treated teeth

restoration for ETT, just $21 \%$ of the participants would place a post frequently or always.

More than half of all respondents (57\%) expected reinforcement for ETT and a decrease of fracture probability when posts are used. Twenty-seven percent expressed the opinion that reinforcement is achieved independently of the type of cementation, while $30 \%$ believed that an adhesive approach is necessary for reinforcement. Only $1 \%$ of the participants still claimed to believe in a purely conventional, non-adhesive approach. Thirty percent agreed with the statement that no reinforcement can be expected from a post.

Most dentists (88 \%) claimed to understand that an embracement of healthy tooth structure (dentine) apical to the finishing line, i.e., the so-called ferrule, increases fracture resistance. Seven percent stated to not believe in this concept.

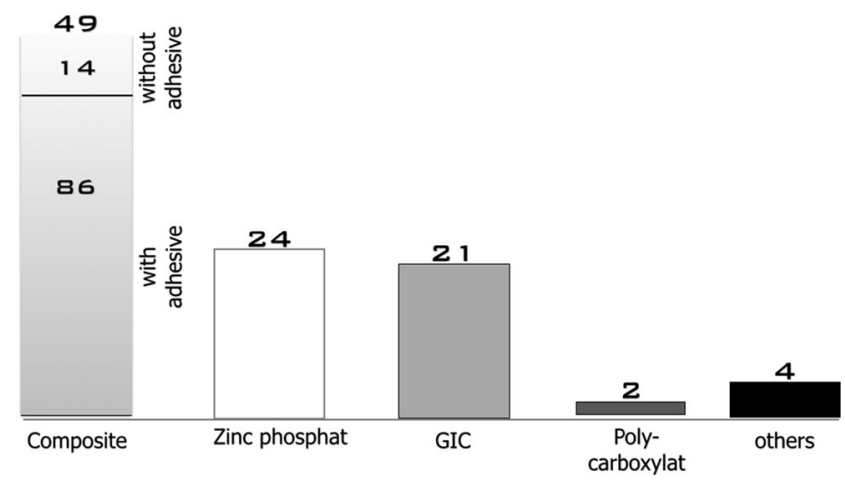

Fig. 1 Which cement you prefer for post cementation 


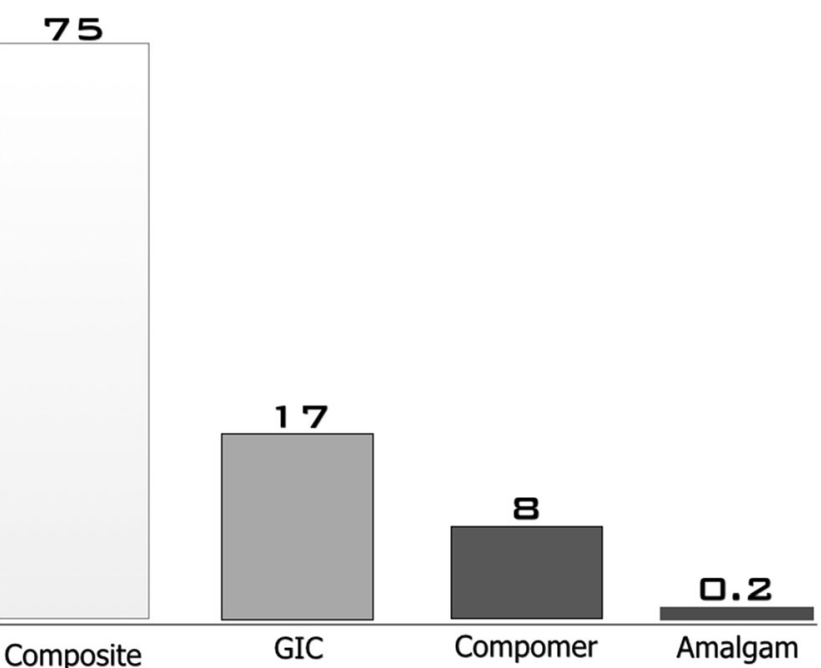

Fig. 2 Which is your favorite core build-up material for post-restoration

Resin composite cements (49\%) were used most frequently, followed by zinc phosphate ( $24 \%$ ), glass-ionomer (GIC) $(21 \%)$, polycarboxylate $(2 \%)$, and other cements $(4 \%)$ to retain endodontic posts. Eighty-six percent of all dentists claimed to prefer composite resin cements with the help of adhesives. In this context, $31 \%$ stated to use self-etch materials, while $45 \%$ stated to apply the classic etch-and-rinse approach. Fourteen percent claimed to lute posts using selfadhesive cements without an additional adhesive (Fig. 1).

When planning for a laboratory restoration, most of the participants $(75 \%)$ stated to use resin composites as core build-up material (Fig. 2). Resin composites as final direct restoration for ETT were used by $85.3 \%$ of the dentists in $65 \%$ (SD $44 \%$ ) of their cases when treating anterior teeth and in $48 \%$ (SD $30 \%$ ) of their cases when treating posterior teeth. In the case of resin composites being used as a permanent direct restoration, the additional use of flowable composite resin material was claimed by $44 \%$ of the dentists, while $14 \%$ did not. For those cases in which flowables were used, the reasons given were "better adaptation" (84\%), "avoiding heterogeneities" (78 \%), "avoiding bacterial leakage" (44\%), "stress breaker" (42\%), and to "save time" (17\%). If dentists answered that they did not use flowables, the reasons given were "lower mechanical strength" (43\%), "no clinical advantage" (40\%), "not able to be sculpted" (36\%),



Fig. 3 Which post type do you used most frequently for post-and-core build-up, when direct restorations are planned

"inappropriate seal" (26\%), and "others" (15\%). In this context, the use of SDR [43], being a bulk-fill flowable with low shrinkage stress, was judged as "convincing" or "very convincing" by $77 \%$ of the respondents. The reasons provided were a subjectively estimated easier application $(88 \%)$, a better adaptation of the material ( $86 \%$ ), and time-saving ( $84 \%$ ). Glass-ionomers (GI) and resin-modified GI were used in 17 and $8 \%$, respectively. Amalgam was very rarely used $(0.2 \%)$.

The preference regarding the post type was stratified by "type of final restoration" (Table 2). Glass-fiber posts were most widely used for direct restorations (69\%), while active metallic posts, i.e., endodontic screws, followed at a reduced frequency (15\%) (Fig. 3). When single crowns were planned, slightly fewer fiber posts (58\%) were placed in favor of endodontic screws (16\%) (Fig. 4). For fixed partial dentures (FPD), glass-fiber posts were preferred by half of all dentists. Metallic active $(17 \%)$ and passive posts $(17 \%)$, i.e., prefabricated posts combined with composite cores, were inserted slightly more often than individually cast post-andcores $(16 \%)$ (Fig. 5). When telescopic crowns were combined with a removable denture, glass-fiber posts remained most popular $(46 \%)$, but individual cast post-and-cores were preferred by $20 \%$ of the respondents (Fig. 6).

Reported reasons for the failure of post-endodontic restoration were crown fracture and failure of the endodontic treatment with $13 \%$ of the respondents each. Loss of post retention
Table 2 The preference regarding post type

\begin{tabular}{llllll}
\hline $\begin{array}{l}\text { Final } \\
\text { restoration }\end{array}$ & $\begin{array}{l}\text { Glass-fiber } \\
\text { post [\%] }\end{array}$ & $\begin{array}{l}\text { Passive } \\
\text { prefabricated } \\
\text { metallic [\%] }\end{array}$ & $\begin{array}{l}\text { Active } \\
\text { prefabricated } \\
\text { metallic post [\%] }\end{array}$ & $\begin{array}{l}\text { Cast post-and-core } \\
{[\%]}\end{array}$ & $\begin{array}{l}\text { Others } \\
{[\%]}\end{array}$ \\
\hline Direct (chair side) & 69 & 12 & 15 & 0.2 & 3 \\
Single crown & 58 & 14 & 16 & 11 & 1 \\
Fixed partial denture & 49 & 17 & 17 & 16 & 1 \\
c-FRPD & 46 & 15 & 17 & 20 & 1 \\
\hline
\end{tabular}

$c$-FRPD combined fixed-removable partial denture 
was mentioned as the third most frequent problem by $11 \%$ of the dentists followed by root fracture $(7 \%)$ and other reasons (10\%).

\section{Discussion}

A nationwide representative survey was conducted to update the recent treatment philosophy and materials used in postendodontic restoration, since the last study of this kind was performed almost a decade ago. We found that glass-fiber posts were the preferred option to be inserted in more than half of the abutment teeth when laboratory restorations are planned. The type of final restoration influenced the type of post chosen. The rationale behind this choice remains unknown. Direct restorations were more frequently used in front teeth without post support ( $20 \%$ of the cases). Adhesive techniques by means of composite resin are popular both for post cementation and core build-up. The majority of dentists claimed to believe in the reinforcement effect of an endodontic post. Nine out of ten respondents expressed their opinion that the ferrule and its effect reduce the risk of fracture of ETT.

The present survey was performed to update the information about current treatment approaches and materials used in post-endodontic restoration in Germany. The questionnaire of this survey is a slightly altered version of the one published in 2006 [44]. The return rate of the questionnaire was $63 \%$. This is in line with response rates reported in other studies, which ranged from 25 to $70 \%[32,33,41]$. Unfortunately, the anonymous nature of the survey did not allow for a reminder mechanism.

The majority of dentists (58\%) agreed with the statement that endodontic posts reinforce ETT. In comparable studies among general practitioners in Sweden, the UK, and the USA, 29, 25, and $59 \%$, respectively, were of the same opinion $[34,35,40]$. In comparison to the survey performed earlier, more than double the respondents in the present survey agreed

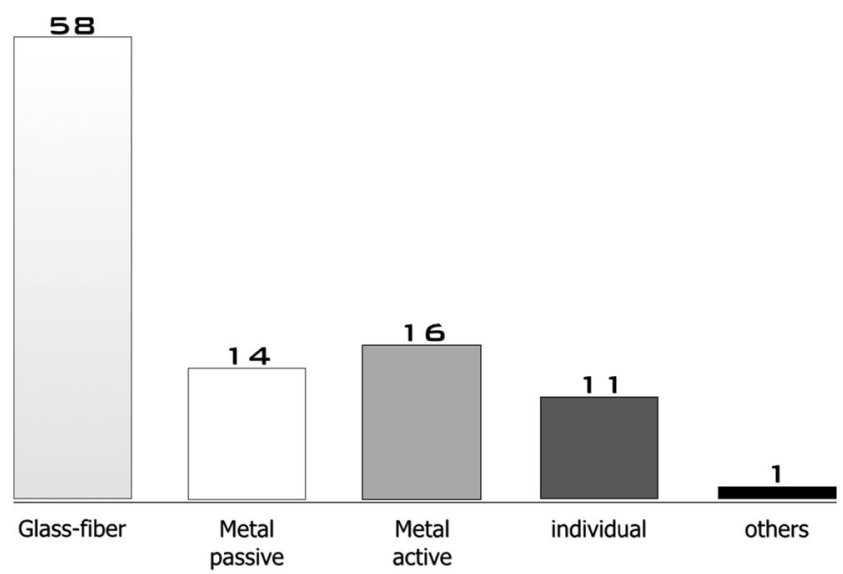

Fig. 4 Which post type do you used most frequently for post-and-core build-up, when single crown restoration are planned

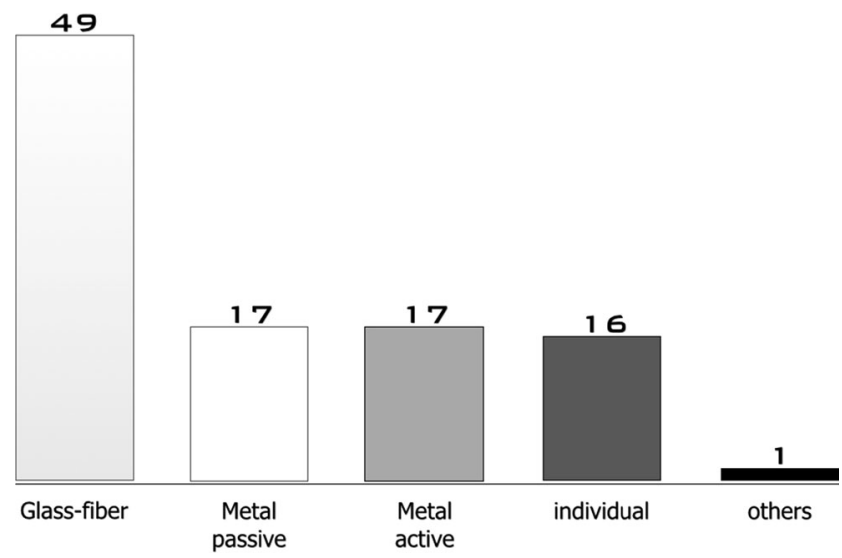

Fig. 5 Which post type do you used most frequently for post-and-core build-up, when FPDs are planned

that a reinforcing effect is to be expected when post placement is performed adhesively, while half of those still agreed that a reinforcing effect would be expected in any case. However, a difference was observed between direct and laboratory restorations: in direct (composite resin) restorations, respondents stated that posts were seldom $(80 \%)$ inserted, while in laboratory restorations, only one third would place a post and it remains unknown what the occasion may be. One may therefore conclude that dentists are aware that a post is not needed for every ETT, but they rather place a post for more "safety," since laboratory restorations are more costly and failure would cause more economic problems. This is contrary to the current state of evidence-based knowledge, which maintains that a post does not result in a reinforcement of the root or tooth, but supports the core build-up [5, 27].

The number of respondents who reported to perceive a reinforcement effect by using the ferrule effect was $88 \%$, which is again higher compared to the earlier study (72\%). The trend appears to be in increasing agreement with the scientific literature. As recently shown in a randomized controlled trial by the present research group, the ferrule effect - and not post material - is key to avoiding clinical failures [1, 2, 45-50].

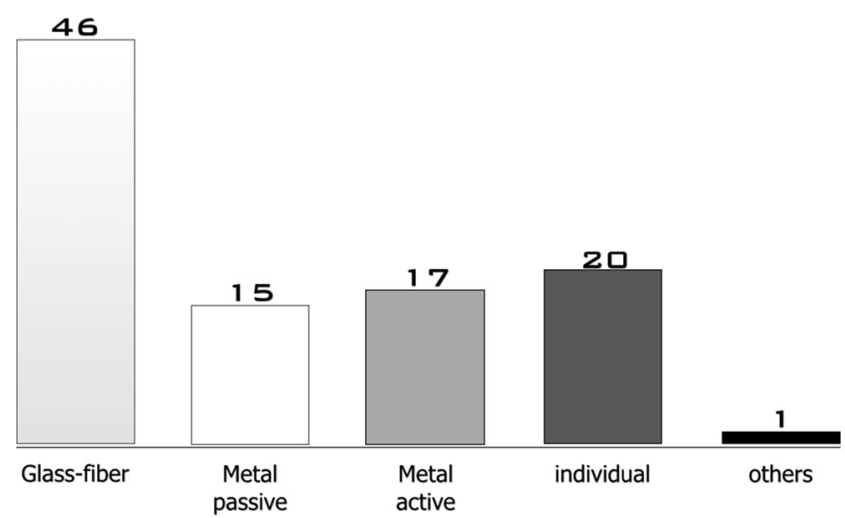

Fig. 6 Which post type do you used most frequently for post-and-core build-up, when telescopic are planned 
At the time of writing this report, there is a preference for prefabricated glass-fiber post systems. Thus, in the last decade, tremendous changes have occurred in the material of choice. This is surprising, since glass-fiber-based endodontic posts are relatively new materials, having been introduced around the year 2000. Interestingly, its use was distinguished between the types of planned final restoration. The more complex and thus costly a restoration is, the more established the choice, i.e., for the most complex prosthodontic restoration of a combined fixed-removable restoration (c-FRPD), the amount of cast post-and-core increased from 11 (for single crowns) to $20 \%$ (c-FRPD). The findings differ clearly from data gathered from Sweden and the UK $[34,35]$ where the cast post-and-cores were the treatment of choice. A positive finding of the present survey is that there is a significant reduction in the reported use of screw posts, which are generally known to introduce stress into tooth hard tissue. Therefore, it is not surprising that root fractures, formerly observed as the third most common cause for failure (26\%), are in the present survey mentioned with an incidence of only $7 \%$ (less than crown fracture, endodontic problems, and loss of post retention). The question remains which decision criteria led to the preferred use of a selected post system. In the scientific literature, no unequivocal final restoration-related evidence-based recommendations exist, may be because the choice of the restoration also depends on the preferences of the dentist and the patient [51].

In contrast to results found in two regions of the UK [32, 34] and the USA [40], where amalgam is popular, amalgam is now rarely used for core foundation procedures in Germany $(0.2 \%)$. This might be due to the fact that within the German population amalgam is still considered to cause health threats such as mercury toxicity. The majority of German dentists uses composite resin (75\%), followed by GI and resinmodified GI ( $25 \%$ overall). With the exception of GI, these results are in agreement with observations made in the USA [40]. While composite resin and amalgam are recommended as core materials, GI was found to be unsuitable, especially for large defects without hard tissue support [52-54]. Less frequent use of GI and RMGI in Germany $(\sim 25 \%)$ compared to earlier data (40\%) might have also contributed to a reduced incidence of failure of the post-endodontic restoration.

Compared to the earlier survey, the treatments performed by German dentists are in general closer to current treatment recommendations published in 2006 [44]. Significant changes in the choice of materials, in favor of adhesive approaches, were found. In particular, the rapid increase in the reported use of glass-fiber posts is astonishing. However, it still remains unclear what criteria determine the specific choice of postendodontic restoration material, in particular with regard to tooth type and type of prosthodontic reconstruction. This finding reflects the current scientific dilemma with in-part equivocal recommendations and missing long-term clinical data.

\section{Conclusions}

Within the limitations of the present study, the following conclusions were drawn:

Glass-fiber posts were the most frequently used restoration material by surveyed dentists in Germany, independent of the prosthodontic restoration planned. Composite resin cores were preferred by three quarters of the dentists. Half of the dentists performed adhesive post placement. There was widely held agreement with the importance of the ferrule and its effect. The majority of dentists reported they would not place a post for direct restoration (single-tooth), while in abutment teeth for laboratory restoration, only one third claimed they would do so.

Acknowledgements The present study has been sponsored in part by DENTSPLY DETREY, Konstanz, Germany. Rainer Seemann is an employee of DENTSPLY DETREY.

Conflict of interest The authors deny any conflicts of interest.

\section{References}

1. Sterzenbach G, Franke A, Naumann M (2012) Rigid versus flexible dentine-like endodontic posts-clinical testing of a biomechanical concept: seven-year results of a randomized controlled clinical pilot trial on endodontically treated abutment teeth with severe hard tissue loss. J Endod 38:1557-63

2. Stankiewicz NR, Wilson PR (2002) The ferrule effect: a literature review. Int Endod J 35:575-81

3. Howe CA, McKendry DJ (1990) Effect of endodontic access preparation on resistance to crown-root fracture. J Am Dent Assoc 121: $712-5$

4. Panitvisai P, Messer HH (1995) Cuspal deflection in molars in relation to endodontic and restorative procedures. J Endod 21:5761

5. Fernandes AS, Dessai GS (2001) Factors affecting the fracture resistance of post-core reconstructed teeth: a review. Int $\mathrm{J}$ Prosthodontics 14:355-63

6. Nagasiri R, Chitmongkolsuk S (2005) Long-term survival of endodontically treated molars without crown coverage: a retrospective cohort study. J Prosthet Dent 93:164-70

7. D'Arcangelo C, Prosperi GD, Passariello P, Caputi S, Malagnino VA (2005) Capacity of coronal dentin to increase fiberglass post retention: a pull-out test. Am J Dent 18:307-10

8. Pereira JR, Mendonca Neto T, Porto Vde C, Pegoraro LF, Valle AL (2005) Influence of the remaining coronal structure on the resistance of teeth with intraradicular retainer. Braz Dent J 16:197-201

9. Naumann M, Koelpin M, Beuer F, Meyer-Lueckel H (2012) 10year survival evaluation for glass-fiber-supported postendodontic restoration: a prospective observational clinical study. J Endod 38: $432-5$

10. Caplan DJ, Kolker J, Rivera EM, Walton RE (2002) Relationship between number of proximal contacts and survival of root canal treated teeth. Int Endod J 35:193-199

11. Naumann M, Blankenstein F, Kiessling S, Dietrich T (2005) Risk factors for failure of glass fiber-reinforced composite post restorations: a prospective observational clinical study. Eur J Oral Sci 113: 519-24 
12. Bergman B, Lundquist P, Sjogren U, Sundquist G (1989) Restorative and endodontic results after treatment with cast posts and cores. J Prosthet Dent 61:10-5

13. Hatzikyriakos AH, Reisis GI, Tsingos N (1992) A 3-year postoperative clinical evaluation of posts and cores beneath existing crowns. J Prosthet Dent 67:454-8

14. Sorensen JA, Martinoff JT (1984) Clinically significant factors in dowel design. J Prosthet Dent 52:28-35

15. Eckerbom M, Magnusson T, Martinsson T (1991) Prevalence of apical periodontitis, crowned teeth and teeth with posts in a Swedish population. Endod Dent Traumatol 7:214-20

16. Ferrari M, Mason PN, Goracci C, Pashley DH, Tay FR (2004) Collagen degradation in endodontically treated teeth after clinical function. J Dent Res 83:414-9

17. Gutmann JL (1992) The dentin-root complex: anatomic and biologic considerations in restoring endodontically treated teeth. $\mathrm{J}$ Prosthet Dent 67:458-67

18. Li LL, Wang ZY, Bai ZC, Mao Y, Gao B, Xin HT, Zhou B, Zhang Y, Liu B (2006) Three-dimensional finite element analysis of weakened roots restored with different cements in combination with titanium alloy posts. Chin Med J (Engl) 119:305-11

19. Assif D, Oren E, Marshak BL, Aviv I (1989) Photoelastic analysis of stress transfer by endodontically treated teeth to the supporting structure using different restorative techniques. J Prosthet Dent 61: $535-43$

20. Saupe WA, Gluskin AH, Radke RA Jr (1996) A comparative study of fracture resistance between morphologic dowel and cores and a resin-reinforced dowel system in the intraradicular restoration of structurally compromised roots. Quintessence Int 27:483-91

21. Aquilino SA, Caplan DJ (2002) Relationship between crown placement and the survival of endodontically treated teeth. J Prosthet Dent 87:256-63

22. Mannocci F, Bertelli E, Sherriff M, Watson TF, Ford TR (2002) Three-year clinical comparison of survival of endodontically treated teeth restored with either full cast coverage or with direct composite restoration. J Prosthet Dent 88:297-301

23. Decock V, De Nayer K, De Boever JA, Dent M (1996) 18-year longitudinal study of cantilevered fixed restorations. Int JProsthodontics 9:331-40

24. Schwartz RS, Robbins JW (2004) Post placement and restoration of endodontically treated teeth: a literature review. J Endod 30:289301

25. Assif D, Gorfil C (1994) Biomechanical considerations in restoring endodontically treated teeth. J Prosthet Dent 71:565-7

26. Lambjerg-Hansen H, Asmussen E (1997) Mechanical properties of endodontic posts. J Oral Rehabil 24:882-7

27. Johnson ME, Stewart GP, Nielsen CJ, Hatton JF (2000) Evaluation of root reinforcement of endodontically treated teeth. Oral Surg Oral Med Oral Pathol Oral Radiol Endod 90:360-4

28. Cohen S, Blanco L, Berman L (2003) Vertical root fractures: clinical and radiographic diagnosis. J Am Dent Assoc 134:434-41

29. Fuss Z, Lustig J, Katz A, Tamse A (2001) An evaluation of endodontically treated vertical root fractured teeth: impact of operative procedures. J Endod 27:46-8

30. Morfis AS (1990) Vertical root fractures. Oral Surg Oral Med Oral Pathol 69:631-5

31. Nair MK, Nair UDP, Grondahl HG, Webber RL, Wallace JA (2001) Detection of artificially induced vertical radicular fractures using tuned aperture computed tomography. Eur J Oral Sci 109:375-9

32. Seow LL, Toh CG, Wilson NH (2003) A survey of current practices among general dental practitioners in Manchester in 2002. Prim Dent Care 10:87-92

33. Brunton PA, Christensen GJ, Cheung SW, Burke FJ, Wilson NH (2005) Contemporary dental practice in the UK: indirect restorations and fixed prosthodontics. Br Dent J 198:99-103, discussion 89
34. Hussey DL, Killough SA (1995) A survey of general dental practitioners' approach to the restoration of root-filled teeth. Int Endod J 28:91-4

35. Eckerbom M, Magnusson T (2001) Restoring endodontically treated teeth: a survey of current opinions among board-certified prosthodontists and general dental practitioners in Sweden. Int $\mathrm{J}$ Prosthodontics 14:245-9

36. Sirimai S, Riis DN, Morgano SM (1999) An in vitro study of the fracture resistance and the incidence of vertical root fracture of pulpless teeth restored with six post-and-core systems. J Prosthet Dent 81:262-9

37. Farrell TH, Burke FJ (1989) Root canal treatment in the General Dental Service 1948-1987. Br Dent J 166:203-8

38. Allen EP, Bayne SC, Cronin RJ Jr, Donovan TE, Kois JC, Summitt JB (2004) Annual review of selected dental literature: Report of the Committee on Scientific Investigation of the American Academy of Restorative Dentistry. J Prosthet Dent 92:39-71

39. Scurria MS, Shugars DA, Hayden WJ, Felton DA (1995) General dentists' patterns of restoring endodontically treated teeth. J Am Dent Assoc 126:775-9

40. Morgano SM, Hashem AF, Fotoohi K, Rose L (1994) A nationwide survey of contemporary philosophies and techniques of restoring endodontically treated teeth. J Prosthet Dent 72:259-67

41. Slaus G, Bottenberg P (2002) A survey of endodontic practice amongst Flemish dentists. Int Endod J 35:759-67

42. Trautmann G, Gutmann JL, Nunn ME, Witherspoon DE, Shulman JD (2000) Restoring teeth that are endodontically treated through existing crowns. Part II: survey of restorative materials commonly used. Quintessence Int 31:719-28

43. Seemann R, Pfefferkorn F, Hickel R (2011) Behaviour of general dental practitioners in Germany regarding posterior restorations with flowable composites. Int Dent J 61:252-6

44. Naumann M, Kiessling S, Seemann R (2006) Treatment concepts for restoration of endodontically treated teeth: a nationwide survey of dentists in Germany. J Prosthet Dent 96:332-8

45. Sorensen JA, Engelman MJ (1990) Ferrule design and fracture resistance of endodontically treated teeth. J Prosthet Dent 63:529 36

46. Isidor F, Brondum K, Ravnholt G (1999) The influence of post length and crown ferrule length on the resistance to cyclic loading of bovine teeth with prefabricated titanium posts. Int J Prosthodontics 12:78-82

47. Zhi-Yue L, Yu-Xing Z (2003) Effects of post-core design and ferrule on fracture resistance of endodontically treated maxillary central incisors. J Prosthet Dent 89:368-73

48. Pierrisnard L, Bohin F, Renault P, Barquins M (2002) Coronoradicular reconstruction of pulpless teeth: a mechanical study using finite element analysis. J Prosthet Dent 88:442-8

49. Sorensen JA, Martinoff JT (1984) Intracoronal reinforcement and coronal coverage: a study of endodontically treated teeth. J Prosthet Dent 51:780-4

50. Guzy GE, Nicholls JI (1979) In vitro comparison of intact endodontically treated teeth with and without endo-post reinforcement. J Prosthet Dent 42:39-44

51. Turp JC, Heydecke G, Krastl G, Pontius O, Antes G, Zitzmann NU (2007) Restoring the fractured root-canal-treated maxillary lateral incisor: in search of an evidence-based approach. Quintessence Int 38:179-91

52. Gateau P, Sabek M, Dailey B (1999) Fatigue testing and microscopic evaluation of post and core restorations under artificial crowns. J Prosthet Dent 82:341-7

53. Ziebert AJ, Dhuru VB (1995) The fracture toughness of various core materials. J Prosthodont 4:33-7

54. Kovarik RE, Breeding LC, Caughman WF (1992) Fatigue life of three core materials under simulated chewing conditions. J Prosthet Dent 68:584-90 